\title{
Relationship, social support, and personality as psychosocial determinants of the risk for postpartum blues
}

\author{
Karolina Maliszewska ${ }^{1}$, Małgorzata Świątkowska-Freund ${ }^{1}$, Mariola Bidzan², Krzysztof Preis \\ ${ }^{1}$ Department of Obstetrics, Medical University of Gdansk, Poland \\ ${ }^{2}$ Institute of Psychology, University of Gdansk, Poland
}

\begin{abstract}
Objectives: The purpose of the study was to identify factors increasing or decreasing the risk for postpartum blues.

Material and methods: A total of 101 women in their first week postpartum were included in the study. The Edinburgh Postnatal Depression Scale, questions concerning their medical and social status, and psychological tests (the Neo-Five Factor Personality Inventory NEO-FFI, the Mieczysław Plopa and Jan Rostowski Marriage Questionnaire, and the Berlin Social Support Scales) were used.

Results: The probability of postpartum blues was detected in $16.8 \%$ of the respondents. The risk decreased with higher satisfaction with intimacy $(O R=0.81)$, partner similarity $(O R=0.78)$, and the overall satisfaction with the relationship $(O R=0.94)$, while higher disappointment elevated that risk $(O R=1.12)$. As far as social support is concerned, further independent factors included perceived available social support $(\mathrm{OR}=0.31)$, perceived instrumental social support $(\mathrm{OR}=0.24)$, need for support $(O R=2.74)$, and protective buffering support $(O R=3.41)$. High level of neuroticism as well as fear of childbirth increased the risk for postpartum blues $(\mathrm{OR}=2.17$ and $\mathrm{OR}=1.30$, respectively). High level of extraversion and better quality of sleep constituted protective factors ( $O R=0.74$ and $O R=0.60$, respectively).

Conclusions: Maternal disappointment with marriage/relationship, neuroticism and introversion, poor quality of sleep, fear of childbirth, and seeking social support are among the factors signaling the need for careful observation for signs of possible postpartum mood disorders both, during hospitalization and the follow-up visits.
\end{abstract}

Key words: psychology, postpartum depression, mental disorders in pregnancy

Ginekologia Polska 2016; 87, 6: 442-447

\section{INTRODUCTION}

Emotional problems have been observed to appear infinitely more often during pregnancy and childbirth as compared to other periods of a woman's life. The most common affective disorders include postpartum/maternal blues ('baby blues syndrome'), postpartum hypomania ('baby pinks'), postpartum depression, and postpartum psychosis. Symptom severity and duration, as well as time of onset constitute the basis for differentiation [1-4]. Some authors use the term 'perinatal disorder', which also includes the pre-partum period [5-7].

Postpartum blues is perceived as a mild and self-limiting disorder of the first days of puerperium. However, it consti- tutes an important risk factor for postpartum depression or anxiety disorders $[1,4,8]$. The following factors have been reported to promote the onset of postpartum disorders: emotional problems during pregnancy (especially depressive symptoms), as well as changes in the hormonal (a decrease in progesterone, estrogen, and thyroid levels after delivery), neurotransmitter (serotonin) and glandular (axis subthalamus - pituitary gland — adrenal gland) systems [9]. The premenstrual syndrome (PMS) is also an example of a correlate of postpartum blues. Lack of social support, family problems - conflicts with partner, stressful life events during pregnancy, single-parent family [1,2], or cohabitation [5], unplanned or unwanted pregnancy, as well as endan- 
gered pregnancy, may also negatively affect the emotional condition of the mother $[3,10]$. Psychological aspects which influence the risk for postpartum disorders include lack of understanding of the newborn's behavior, the actual, real picture of motherhood as opposed to the imagined one, pessimism, low self-esteem, and high level of neuroticism [1, 3, 7].

In 1987, J.L. Cox, J.M. Holden, and R. Sagovsky developed a screening test known as the Edinburgh Postnatal Depression Scale (EPDS), consisting of 10 questions, with the score from 0 to 30 and with most often assumed cut-off scores of $9 / 10$ or $12 / 13$ points [11]. In case of a positive result, further clinical evaluation is essential. The test is a screening tool used in secondary prophylaxis and perinatology and postpartum affective disorders $[1,2,12]$.

\section{OBJECTIVES}

The purpose of the study was to investigate factors promoting the risk for postpartum blues.

\section{MATERIAL AND METHODS}

A group of 101 women, who gave birth at the Obstetric Clinic of Medical University in Gdańsk, between December 2011 and March 2012, were included in the study. They filled out a questionnaire in the first days of hospitalization after childbirth. Written informed consent was obtained from all participants. Local Ethics Committee approved of the study (NKEBN/531/2011-2012).

A questionnaire containing EPDS, questions about social and medical status, and a number of standardized psychological scales: The Mieczysław Plopa and Jan Rostowski Marriage Questionnaire (KDM-2), the Berlin Social Support Scales (BSSS), and the NEO Five-Factor Personality Inventory (NEO-FFI), were used. In EPDS, a score of 13 was used as the cut-off point, analogically to the risk for postpartum depression evaluation.

KDM-2 consists of 5 scales measuring marriage dimensions: intimacy, similarity, self-realization, disappointment, and the total score (global assessment of relationship/marriage) [13]. Raw scores were used in our study. Women in informal partnerships were also asked to fill out the questionnaire in order to assess this relationship. BSSS includes the following scales: perceived available support, need for support, support seeking, currently received support, and protective-buffering scale, and subscales: emotional support, and informational support (each included in the subscales of perceived available and currently received support). The result is an arithmetical mean of a scale or subscale in the range of 1-4 [14]. NEO-FFI consists of five parameters: Neuroticism (N), Extraversion $(\mathrm{E})$, Openness to experience ( $(O)$, Agreeableness ( $A)$, and Conscientiousness (C). Raw scores are converted into a standardized 10-point scale [15]. Scores for quality of sleep, fear of childbirth, and delivery pain were noted on a 10-point scale, just like the Numerical Rating Scale (NRS) used for pain.

Statistical analysis was conducted using STATISTICA 10 software with the following tests: Shapiro-Wilk, t-Student, U Mann-Whitney, and $\mathrm{Chi}^{2}$. Univariate and multivariate logistic regressions were also used. Data have been shown as arithmetic means and standard deviation, or as a number with the percentage of the sample [n (\%)]. The p-value of $<0.05$ was considered as statistically significant.

\section{RESULTS}

The study group included 101 mothers who filled out the questionnaire on day 2.50 (SD 1.37) after childbirth. Mean EPDS score was 7.92 (SD 4.37) points. Mean patient age was 30.07 (SD 4.76) years. Gestational age at delivery was 39.16 (SD 2.22) weeks. Vaginal delivery was more common than cesarean section (60.4\%). Labor pain was assessed as 8.04 (SD 3.03) points on a 10-point rating scale. The majority of the investigated patients were residents of big cities (73.3\%), had higher education (B.A. or M.A.) (76.2\%), and were professionally active during pregnancy (82.2\%). Most respondents were married (76.2\%). Over half of the women (55.4\%) were primiparous; $57.4 \%$ of the patients reported no PMS complaints. Quality of sleep postpartum and fear of childbirth were assessed with the use of a 10-point rating scale, mean 6.33 (SD 2.11) and 5.36 (SD 3.01) points, respectively (Table 1 ).

The group was subsequently divided based on the EPDS result: at risk ( $n=17, \mathrm{RPPB}$ ) and free of risk for postpartum blues ( $n=84$, NRPPB). The subgroups were statistically significantly different in terms of EPDS scores (6.54 SD 3.31 vs. 15.77 SD $1.72, p=0.005$ ), sleep quality after delivery $(p<0.01)$, and fear of childbirth $(p=0.01)$ (Table 1$)$. In the univariate regression analysis, the following factors were linked with the risk for postpartum blues: higher quality of sleep: $\mathrm{OR}=0.72,95 \% \mathrm{Cl} 0.55-0.93 ; \mathrm{p}=0.01$ and higher fear of childbirth: $\mathrm{OR}=1.30,95 \% \mathrm{Cl} 1.05-1.60 ; \mathrm{p}=0.02$ ).

Subsequently, we analyzed the correlation between the quality of the relationship (KDM-2) and the probability of developing a postpartum mental disorder. Statistically significant differences were found between the subgroups in all scales of the test (Table 2). Patients at risk for postpartum blues reported lower levels of satisfaction with intimacy $(p<0.001)$, self-realization $(p=0.02)$, and partner similarity $(p=0.002)$, as well as greater disappointment with marriage/relationship ( $p<0.001)$, and lower overall assessment of marriage/relationship $(p<0.001)$. The risk for postpartum blues decreased with increasing intimacy $(O R=0.81$, $p=0.02)$, partner similarity $(O R=0.78, p=0.003)$, and overall satisfaction with marriage/relationship (OR $=0.94$, $p=0.002)$. Higher disappointment increased the risk for postpartum blues $(\mathrm{OR}=1.12, \mathrm{p}=0.009)$ (Table 2$)$. 


\begin{tabular}{|c|c|c|c|c|}
\hline & $\begin{array}{l}\text { NRPPB } \\
n=84\end{array}$ & $\begin{array}{l}\text { RPPB } \\
n=17\end{array}$ & $\mathbf{p}$ & $\begin{array}{c}\text { Total } \\
n=101\end{array}$ \\
\hline EPDS result & $6.54 \pm 3.31$ & $14.77 \pm 1.72$ & 0.005 & $7.92 \pm 4.37$ \\
\hline Age (years) & $30.15 \pm 4.67$ & $29.65 \pm 5.30$ & 0.69 & $30.07 \pm 4.76$ \\
\hline Gestational week at delivery & $39.13 \pm 2.29$ & $39.29 \pm 1.93$ & 0.92 & $39.16 \pm 2.22$ \\
\hline \multicolumn{5}{|l|}{ Mode of delivery $n(\%)$} \\
\hline Vaginal delivery & $58(69.1)$ & $3(17.7)$ & \multirow{2}{*}{0.27} & $61(60.4)$ \\
\hline Cesarean section & $26(30.9)$ & $14(82.3)$ & & $40(39.6)$ \\
\hline Delivery pain (scale 0-10) & $7.85 \pm 3.21$ & $9.0 \pm 1.36$ & 0.39 & $8.04 \pm 3.03$ \\
\hline \multicolumn{5}{|l|}{ Place of inhabitance $n(\%)$} \\
\hline City $>100,000$ inhabitants & $62(73.8)$ & $12(70.6)$ & \multirow{2}{*}{0.78} & $74(73.3)$ \\
\hline City $<100,000$ inhabitants and rural areas & $22(26.1)$ & $5(29.4)$ & & $27(26.7)$ \\
\hline \multicolumn{5}{|l|}{ Education n (\%) } \\
\hline Elementary and vocational & $3(3.57)$ & $0(0)$ & \multirow{3}{*}{0.49} & $3(2.9)$ \\
\hline High school & $16(19.1)$ & $5(29.4)$ & & $21(20.8)$ \\
\hline Higher & $65(77.4)$ & $12(70.6)$ & & $77(76.2)$ \\
\hline \multicolumn{5}{|l|}{ Professional activity $\mathrm{n}(\%)$} \\
\hline Yes & $69(83.1)$ & $14(82.4)$ & \multirow{2}{*}{0.94} & $83(82.2)$ \\
\hline No & $14(16.9)$ & $3(17.6)$ & & $17(16.8)$ \\
\hline \multicolumn{5}{|l|}{ Relationship with the father of the child $n(\%)$} \\
\hline Marriage & $66(78.57)$ & $11(64.7)$ & \multirow{4}{*}{0.23} & $77(76.2)$ \\
\hline Engagement & $6(7.14)$ & $3(17.65)$ & & $9(8.9)$ \\
\hline Stable relationship & $7(8.33)$ & $3(17.65)$ & & $10(9.9)$ \\
\hline Other (rare or no contact) & $5(5.95)$ & $0(0)$ & & $5(4.5)$ \\
\hline \multicolumn{5}{|l|}{ Parity n (\%) } \\
\hline Primiparous & $47(56)$ & $9(53)$ & \multirow{2}{*}{0.43} & $56(55.4)$ \\
\hline Multiparous & $37(44)$ & $8(47)$ & & $45(44.6)$ \\
\hline \multicolumn{5}{|l|}{ PMS n (\%) } \\
\hline Yes & $24(28.9)$ & $9(52.9)$ & \multirow{3}{*}{0.11} & $33(32.7)$ \\
\hline No & $52(62.7)$ & $6(35.3)$ & & $58(57.4)$ \\
\hline I don't know & $7(8.4)$ & $2(11.8)$ & & $9(8.9)$ \\
\hline Sleep quality after delivery (scale $0-10$ ) & $6.58 \pm 2.03$ & $5.12 \pm 2.1$ & $<0.01$ & $6.33 \pm 2.11$ \\
\hline Fear of childbirth (scale $0-10$ ) & $5.02 \pm 2.97$ & $7.06 \pm 2.68$ & 0.01 & $5.36 \pm 3.01$ \\
\hline Puerperium day when the questionnaire was completed & $2.46 \pm 1.40$ & $2.71 \pm 1.12$ & 0.30 & $2.50 \pm 1.37$ \\
\hline
\end{tabular}

NRPPB — no risk for postpartum blues; RPPB — risk for postpartum blues; $\mathrm{n}$ - number; $\mathrm{p}$ - $\mathrm{p}$ value; EPDS — Edinburgh Postnatal Depression Scale; PMS - premenstrual syndrome

Table 2. Comparison of KDM-2 results of women at risk and no risk for postpartum blues. Odds ratio from logistic regression

\begin{tabular}{|l|c|c|c|c|c|c|}
\hline & $\begin{array}{c}\text { NRPPB } \\
\mathbf{n = 8 4}\end{array}$ & $\begin{array}{c}\text { RPPB } \\
\mathbf{n = 1 7}\end{array}$ & $\mathbf{p}$ & OR & 95\% CI \\
\hline Intimacy & $35.04 \pm 4.04$ & $30.71 \pm 4.69$ & $<0.001$ & 0.81 & $0.71-0.93$ \\
\hline Self-realization & $30.04 \pm 3.92$ & $27.94 \pm 3.21$ & 0.02 & 0.89 & $0.76-1.00$ \\
\hline Similarity & $31.04 \pm 3.38$ & $27.88 \pm 3.66$ & 0.002 & 0.78 & $0.66-0.91$ \\
\hline Disappointment & $15.20 \pm 5.63$ & $20.24 \pm 3.58$ & $<0.001$ & 1.12 & $1.02-1.22$ \\
\hline Total & $140.69 \pm 13.37$ & $126.29 \pm 15.86$ & $<0.001$ & 0.94 & 0.003 \\
\hline
\end{tabular}

KDM-2 - Mieczyslaw Plopa and Jan Rostowski Marriage Questionnaire; NRPPB — no risk for postpartum blues; RPPB — risk for postpartum blues; $\mathrm{n}$ — number; $\mathrm{p}-\mathrm{p}$ value; $\mathrm{OR}$ - odds ratio; $\mathrm{Cl}$ - confidence interval 


\begin{tabular}{|c|c|c|c|c|c|c|}
\hline Social support & $\begin{array}{c}\text { NRPPB } \\
n=84\end{array}$ & $\begin{array}{l}\text { RPPB } \\
n=17\end{array}$ & $\mathbf{p}$ & OR & $95 \% \mathrm{Cl}$ & $\mathbf{p}$ \\
\hline Perceived available & $3.73 \pm 0.37$ & $3.51 \pm 0.51$ & 0.003 & 0.31 & $0.01-1.00$ & 0.04 \\
\hline Perceived available emotional & $3.65 \pm 0.48$ & $3.5 \pm 0.48$ & 0.16 & 0,57 & $0.21-1.53$ & 0.26 \\
\hline Perceived available instrumental & $3.83 \pm 0.35$ & $3.51 \pm 0.61$ & 0.02 & 0.24 & $0.08-0.75$ & 0.01 \\
\hline Need for support & $2.88 \pm 0.56$ & $3.19 \pm 0.61$ & 0.07 & 2.74 & $1.0-7.52$ & 0.048 \\
\hline Support seeking & $2.95 \pm 0.57$ & $3.15 \pm 0.69$ & 0.30 & 1.80 & $0.73-4.51$ & 0.20 \\
\hline Currently received & $3.84 \pm 0.31$ & $3.56 \pm 0.44$ & 0.01 & 0.29 & $0.08-1.07$ & 0.06 \\
\hline Currently received emotional & $3.87 \pm 0.30$ & $3.69 \pm 0.41$ & 0.02 & 0.27 & $0.07-1.10$ & 0.06 \\
\hline Currently received informational & $3.85 \pm 0.35$ & $3.69 \pm 0.46$ & 0.19 & 0.39 & $0.11-1.30$ & 0.12 \\
\hline Currently received instrumental & $3.63 \pm 0.64$ & $3.38 \pm 0.78$ & 0.07 & 0.62 & $0.31-1.23$ & 0.17 \\
\hline Satisfaction with support & $3.93 \pm 0.37$ & $3.76 \pm 0.44$ & 0.23 & 0.45 & $0.15-1.37$ & 0.16 \\
\hline Buffering-protective scale & $1.85 \pm 0.60$ & $2.29 \pm 0.38$ & 0.001 & 3.41 & $1.36-8.51$ & 0.008 \\
\hline
\end{tabular}

BSSS - Berlin Social Support Scales; NRPPB — no risk for postpartum blues; RPPB — risk for postpartum blues; $n$ - number; $p$ - $p$ value; OR — odds ratio; $\mathrm{Cl}$ - confidence interval

\begin{tabular}{|c|c|c|c|c|c|c|c|}
\hline \multicolumn{6}{|c|}{ Table 4. Comparison of NEO-FFI results of women at risk and no risk for postpartum blues. Odds ratio from logistic regression } \\
\hline & $\begin{array}{c}\text { NRPPB } \\
\mathbf{n = 8 4}\end{array}$ & $\begin{array}{c}\text { RPPB } \\
\mathbf{n}=17\end{array}$ & $\mathbf{p}$ & OR & $95 \%$ Cl & $\mathbf{p}$ \\
\hline $\mathbf{N}$ & $3.45 \pm 1.7$ & $5.88 \pm 1.70$ & $<0.001$ & 2.17 & $1.48-3.18$ & $<0.001$ \\
\hline E & $6.32 \pm 2.0$ & $5.06 \pm 2.25$ & 0.04 & 0.74 & $0.57-0.97$ & 0.02 \\
\hline $\mathbf{O}$ & $5.25 \pm 2.1$ & $4.53 \pm 2.15$ & 0.20 & 0.85 & $0.65-1.09$ & 0.20 \\
\hline $\mathbf{A}$ & $5.71 \pm 2.08$ & $5.24 \pm 2.08$ & 0.46 & 0.89 & $0.69-1.15$ & 0.39 \\
\hline $\mathbf{C}$ & $7.13 \pm 2.37$ & $5.94 \pm 1.89$ & 0.04 & 0.80 & $0.63-1.01$ & 0.06 \\
\hline
\end{tabular}

NEO-FFI — Neo-Five Factor Personality Inventory; NRPPB — no risk for postpartum blues; RPPB — risk for postpartum blues; $n$ - number; $\mathrm{p}$ - $\mathrm{p}$ value; OR — odds ratio; $\mathrm{Cl}$ - confidence interval; $\mathrm{N}$ - Neuroticism; $\mathrm{E}$ - Extraversion; $\mathrm{O}$ - Openness to experience; $\mathrm{A}$ - Agreeableness; $\mathrm{C}$ - Conscientiousness

\begin{tabular}{|l|c|c|}
\hline Table 5. Risk for postpartum blues with regard to the selected determinants. Fully adjusted model & a. \\
\hline Parameter & a. Cl \\
\hline Sleep quality after delivery (scale 0-10) & 0.33 & $0.14-0.80$ \\
\hline Perceived available instrumental social support (BSSS) & 0 & $0-5.1$ \\
\hline Need for social support (BSSS) & 14.16 & $1-190$ \\
\hline Currently received social support (BSSS) & 0.01 \\
\hline N (NEO-FFI) & 0.01 & $0-659$ \\
\hline E (NEO-FFI) & 1.89 & $0.94-3.81$ \\
\hline Intimacy (KDM-2) & 0.51 & $0.27-0.95$ \\
\hline Self-realization (KDM-2) & 0.05 \\
\hline Similarity (KDM-2) & 0.56 & $0.19-1.67$ \\
\hline Disappointment (KDM-2) & 0.04 \\
\hline Total (global assessment of relationship/marriage, KDM-2) & 0.78 & $0.32-1.89$ \\
\hline
\end{tabular}

BSSS — Berlin Social Support Scales; NEO-FFi — Neo-Five Factor Personality Inventory; KDM-2 — Mieczylaw Plopa and Jan Rostowski Marriage Questionnaire; aOR — adjusted odds ratio; $\mathrm{Cl}$ - confidence interval; $\mathrm{p}$ - $\mathrm{p}$-value

Statistical analysis of social support aspects yielded statistically significant differences between the subgroups. Patients at risk for postpartum blues obtained lower scores in the following social support areas: perceived available $(p=0.003)$, perceived available instrumental $(p=0.02)$, currently received $(p=0.01)$, currently received emotional $(p=0.02)$, and higher scores in the buffering-protective scale $(p=0.001)$. Univariate analysis of regression proved 
perceived available social support $(\mathrm{OR}=0.31, \mathrm{p}=0.04)$, perceived instrumental $(O R=0.24, p=0.01)$, need for support $(\mathrm{OR}=2.74, \mathrm{p}=0.0048)$, and the buffering-protective scale $(\mathrm{OR}=3.41, \mathrm{p}=0.008)$ to be independent factors correlated with the risk for postpartum blues syndrome (Table 3 ).

Women at risk for postpartum blues presented a significantly higher level of neuroticism $(p<0.001)$, and lower level of extraversion and conscientiousness $(p=0.04)$. Higher scores on neuroticism increased the risk for 'baby blues' $(O R=2.17, p<0.001)$, while extraversion decreased that risk $(\mathrm{OR}=0.74, \mathrm{p}=0.02)$ (Table 4$)$.

Multivariate analysis of regression was used to create a model of dependent factors favoring the onset of postpartum blues. The model includes sleep quality, extraversion, and need for social support. An increase in the first two factors decreases the risk for postpartum blues $(\mathrm{aOR}=0.33$, $\mathrm{p}=0.01 ; \mathrm{aOR}=0.51, \mathrm{p}=0.04$ ), while an increase in the need for social support elevated that risk $(a O R=14.16, p<0.05)$ (Table 5).

\section{DISCUSSION}

The rationale behind the proposed methodology is the possibility of identifying postpartum blues already during a short hospitalization after delivery. Delayed identification of high-risk for postpartum depression patients, 4 to 6 weeks later in ambulatory conditions, presents a challenge.

In our study, we have proven that most socio-demographic factors do not affect the risk for postpartum blues. We found no correlations between PMS, education, professional activity, or type of relationship and the risk postpartum blues, which stands in opposition to other findings in the literature $[1,3,5,16,17]$, possibly due to inaccuracies in methodology, i.e. different research tools (EPDS, Beck Depression Inventory, Patient Health Questionnaire 2), different diagnostic criteria, or small sample size.

Low-quality relationship with the partner may negatively affect maternal emotional condition. Low level of self-realization may lead to low stability and satisfaction. In contrast, high scores in intimacy and partner similarity might function as predictors of receiving support from the partner, or a chance for a conversation on intimate subjects such as delivery, puerperium, and care of the newborn. The role of relationship quality in the development of postpartum mental disorders has been widely reported $[1,3,18,19]$.

Social support is yet another crucial factor influencing the onset of postpartum blues. Instrumental support which provides the mother with specific instructions is important in the new, difficult situation such as motherhood. Women at risk for 'baby blues' think they will receive less support from close family (especially instrumental support) and that they need it more. Higher scores on the buffering-protective scale suggest shielding others from bad news, so the patient does not inform a close relative about her low mood, which may also facilitate easier development of postpartum blues. In summary, the following patients beliefs constitute the risk factors for postpartum blues: 'I need support (need), but I will not receive as much as I need (perceived available), especially specific instructions (instrumental), and I will not admit to being in a bad mood (buffering-protective scale)' The role of social support has been confirmed by numerous studies $[16,20]$.

Neuroticism - a personality trait which is associated with the risk for postpartum blues - was investigated with NEO-FFI. Neurotic women (i.e. with high neuroticism scores) are poorly adaptable, emotionally unstable, and show a generalized tendency to feel negative emotions. Their mechanisms of coping with stress and adaptive mechanisms are poor. Faced with the challenge of motherhood, they become easily depressive, which has been widely reported in the literature [7]. Fear of childbirth, a derivative of this trait, has also proven to be significant in our study, which is consistent with other reports [21, 22]. A high level of extraversion seems to be a protective factor as sociability and contacts with other people may allow to discuss current emotions with them and lessen the inner tension, contrary to the report of Podolska et al. [7].

Lower quality of sleep is another risk factor for postpartum blues syndrome, which is consistent with the literature $[23,24]$. In our study, we observed a correlation between sleep disorders and maternal blues. However, it is not possible to determine the cause-and-effect direction.

Admittedly, our study was conducted during the period specific for postpartum blues (first week), while EPDS is typically used to screen for postpartum depression [1]. The percentage of patients at risk for postpartum blues (16.8\%) corresponds to the incidence of postpartum depression (13-19\%) [25], not postpartum blues (80-85\%) [1]. Lack of unequivocal agreement on postpartum mental disorders suggests the need for further studies. The idea of determining a separate cut-off score in EPDS for postpartum blues (as suggested by Cox et al. — 9/10) [11], or creating a separate validated tool, seems promising. In light of the abovementioned data and literature reports, it seems prudent to include additional questions about confirmed risk factors.

Postpartum care provided by midwives in the ambulatory settings may be satisfactory for the patients [26]. It is worth including an evaluation of maternal emotional condition, especially when some risk factors are present.

The obtained results do not prove the cause-and-effect relationship in an explicit way, but they may be useful for authors of different projects (i.e. clinical-cohort studies). The possibility that unsatisfactory relationship or social support negatively affect the current emotional state of a patient ought to be excluded. 
Our paper is a preliminary report. Larger sample size studies are currently being conducted and the findings will be published soon.

\section{CONCLUSIONS}

Poor quality of marriage/relationship in terms of intimacy, partner similarity and disappointment negatively correlate with the risk for postpartum blues. As far as social support is concerned, expected support and the conviction that the patient will receive helpful instructions are protective factors for postpartum blues. Higher need for support and hiding low mood increase the risk for postpartum blues. Personality of a patient constitutes yet another important aspect. High level of neuroticism (including fear of childbirth) and low level of extraversion are associated with the risk as well. It is vital to evaluate relationship status, social support, quality of sleep, fear of childbirth, and personality traits in women after childbirth to detect possible postpartum mental disorders.

\section{REFERENCES}

1. Bielawska-Batorowicz E. Zaburzenia emocjonalne po porodzie. In: Bielawska-Batorowicz E. (ed.). Wydawnictwo Naukowe Śląsk, Katowice 2006, 221-253.

2. Koszewska I. O depresji w ciąży i po porodzie. Wydawnictwo Lekarskie PZWL, Warszawa 2010

3. Wasilewska-Pordes M. Depresja porodowa. Wydawnictwo Radamsa, Kraków 2001.

4. Jaeschke R, Siwek M, Dudek D. Poporodowe zaburzenia nastroju — update 2012. Neuropsychiatria i Neuropsychologia. 2012, 7, 113-121.

5. Podolska MZ, Majkowicz M, Sipak-Szmigiel O, [et al.]. Cohabitation as a strong predicting factor of perinatal depression. Ginekol Pol. 2009, 80, 280-284.

6. Podolska MZ, Majkowicz M, Sipak-Szmigiel O, [et al.]. Personality profiles of pregnant and postpartum women with symptoms of perinatal depression: The differences of self image in the sphere of psychological needs. Ginekol Pol. 2009, 80, 343-347.

7. Podolska MZ, Bidzan M, Majkowicz M, [et al.]. Personality traits assessed by the neo five-factor inventory (neo-ffi) as part of the perinatal depression screening program. Med Sci Monit. 2010, 16, 77-81.

8. Reck C, Stehle E, Reinig K, [et al.]. Maternity blues as a predictor of dsm-iv depression and anxiety disorders in the first three months postpartum. J Affect Disord. 2009, 113, 77-87.

9. Doornbos B, Fekkes D, Tanke MA, [et al.]. Sequential serotonin and noradrenalin associated processes involved in postpartum blues. Prog Neuropsychopharmacol Biol Psychiatry. 2008, 32, 1320-1325.
10. Kossakowska-Petrycka K, Walecka-Matyja K. Psychological causative factors in postpartum depression amongst women with normal and high-risk pregnancies. Ginekol Pol. 2007, 78, 544-548.

11. Cox JL, Holden JM, Sagovsky R. Detection of postnatal depression. Development of the 10-item edinburgh postnatal depression scale. $\mathrm{Br}$ J Psychiatry. 1987, 150, 782-786.

12. Bielawska-Batorowicz E. Edynburska skala do pomiaru depresji In: Bielawska-Batorowicz E. (ed.). Determinanty spostrzegania dziecka przez rodziców w okresie poporodowym. Wydawnictwo Uniwersytetu Łódzkiego, Łódź 1995, 97-98.

13. Plopa M. Psychologia rodziny teoria i badania. Wyd. 6. Oficyna wydawnicza Impuls, Kraków 2011.

14. Łuszczyńska A, Mazurkiewicz M, Kowalska M, [et al.]. Berlińskie skale wsparcia społecznego (bsss): Wyniki wstępnych badań nad adaptacją skal i ich własnościami psychometrycznymi. Studia Psychologiczne. 2006, 44, 17-27.

15. Zawadzki B, Strelau J, Szczepaniak P, [et al.]. Neoffi — inwentarz osobowości neoffi. Pracownia Testów Psychologicznych Polskiego Towarzystwa Psychologicznego, Warszawa 1998.

16. Gjerdingen $D$, McGovern $P$, Attanasio $L$, [et al.]. Maternal depressive symptoms, employment, and social support. J Am Board Fam Med. 2014, 27, 87-96.

17. Rubertsson C, Wickberg B, Gustavsson $\mathrm{P}_{\text {, }}$ [et al.]. Depressive symptoms in early pregnancy, two months and one year postpartum-prevalence and psychosocial risk factors in a national swedish sample. Arch Womens Ment Health. 2005, 8, 97-104.

18. Mamun AA, Clavarino AM, Najman JM, [et al.]. Maternal depression and the quality of marital relationship: A 14-year prospective study.J Womens Health (Larchmt). 2009, 18, 2023-2031.

19. Lutkiewicz K, Bidzan M. Sexual activity of pregnant polish women and the assessment of the marital relation quality. Health Psychology Report. 2013, 1, 9-17.

20. Kim TH, Connolly JA, Tamim H. The effect of social support around pregnancy on postpartum depression among canadian teen mothers and adult mothers in the maternity experiences survey. BMC Pregnancy Childbirth. 2014, 14, 162.

21. Podolska MZ, Majkowicz M, Sipak-Szmigiel O, [et al]. Ways of coping in stressful situations and anxiety-state or anxiety-trait among women with symptoms of perinatal depression. Ginekol Pol. 2009, 80, 201-206.

22. Mojs E, Czarnecka-Iwanczuk M, Glowacka MD. The level of anxiety and depression in the early puerperium - preliminary communication. Psychiatr Pol. 2013, 47, 31-40.

23. Coo S, Milgrom J, Kuppens $P$, [et al]. Exploring the association between maternal mood and self-reports of sleep during the perinatal period. J Obstet Gynecol Neonatal Nurs. 2014, 43, 465-477.

24. Romero-Gutierrez G, Duenas-de la Rosa EM, Regalado-Cedillo CA, [et al.]. [Prevalence of maternal sadness and its associated factors]. Ginecol Obstet Mex. 2010, 78, 53-57.

25. O'Hara MW, McCabe JE. Postpartum depression: Current status and future directions. Ann Rev Clin Psychol. 2013, 9, 379-407.

26. Niewiadomski T, Biskupska M, Wysocki J. Patient satisfaction with primary health care rendered by community midwives in the area of poznan. Ginekol Pol. 2014, 85, 37-42. 